$$
(1-q) \frac{L}{R t}=\frac{5}{2} \log \frac{t}{t_{c}}-\log \frac{p}{p_{c}} \quad . \quad . \quad .
$$

Assuming that real substances may be considered to approach this ideal, we can substitute in equation (3) experimental values of boiling points and heats of evaporation at a given pressure, say, atmospheric, and the critical temperatures and pressures, and so calculate values of $q$ (Table 2).

TABle 2. CAlculated VAlUes of $q$ For ideal conditions.

$\begin{array}{ccccccccc}\text { Substance } & \mathrm{He} & \mathrm{H}_{2} & \mathrm{~N}_{2} & \mathrm{O}_{2} & \mathrm{HCl} & \mathrm{Cl}_{2} & \mathrm{CO}_{2} & \mathrm{CS}_{2} \\ q & 0.840 & 0.745 & 0.755 & 0.720 & 0.715 & 0.692 & 0.805 & 0.735 \\ \text { Substance } & \mathrm{C}_{8} \mathrm{H}_{8} & \mathrm{C}_{8} \mathrm{H}_{7} \mathrm{~N} & \mathrm{NO} & \mathrm{NH}_{3} & \mathrm{C}_{2} \mathrm{H}_{8} \mathrm{OH} & \mathrm{H}_{2} \mathrm{O} \\ q & & 0.742 & 0.741 & 0.752 & 0.720 & 0.768 & 0.693\end{array}$

It is immediately obvious from Table 2 that the values of $q$ so calculated are nearly equal for all the substances. The average is $0 \cdot 746$, which is nearly equal to $0 \cdot 75$. This may be of significance, since it gives a whole number ratio, $3 / 1$, of molecules in the vapour phase to molecules in the liquid phase.

Thus a number of real substances behave approximately in such a way that their heats of vaporization and boiling points at atmospheric pressure are related to their critical temperatures and pressures as would be those of an ideal substance having the perfect gas laws for its saturated vapour, and a constant entropy for its mixture containing 3 molecules of vapour to 1 of liquid. The $3 / 1$ ratio may be related to the packing volume of spherical symmetry.

It will be clear that use of this idea, and consequently substituting $q=0.75$ in equation (3), will predict values of $\frac{L}{t}$, so that the suggestion gives something corresponding to Trouton's rule. But Table 3, which compares experimental values of $\frac{L}{t}$ with values calculated on $q=0.75$, shows it is more accurate than Trouton's rule.

\begin{tabular}{|c|c|c|c|c|c|c|c|c|}
\hline \multirow[b]{2}{*}{$\begin{array}{l}\text { Substance } \\
\frac{L}{t}\left\{\begin{array}{l}\text { Expt. } \\
\text { Calc. }\end{array}\right.\end{array}$} & \multirow[b]{2}{*}{$\begin{array}{l}\mathrm{He} \\
5 \cdot 1 \\
3 \cdot 3\end{array}$} & \multicolumn{4}{|c|}{ TABLE 3.} & & \multirow[b]{2}{*}{$\begin{array}{c}\mathrm{CS}_{2} \\
21 \\
22 \cdot 1\end{array}$} \\
\hline & & $\begin{array}{c}\mathrm{H}_{2} \\
10 \cdot 8 \\
11 \cdot 0\end{array}$ & $\begin{array}{l}\mathrm{N}_{2} \\
17 \cdot 3 \\
17 \cdot 1\end{array}$ & $\begin{array}{c}\mathrm{O}_{2} \\
18 \cdot 1 \\
20 \cdot 2\end{array}$ & $\begin{array}{l}\mathrm{HCl} \\
20 \cdot 7 \\
23.7\end{array}$ & $\begin{array}{r}\mathrm{Cl}_{2} \\
19 \cdot 2 \\
23 \cdot 6\end{array}$ & $\begin{array}{c}\mathrm{CO}_{2} \\
31 \\
24 \cdot 3\end{array}$ & \\
\hline $\begin{array}{l}\text { Substar } \\
\frac{L}{t}\left\{\begin{array}{l}\text { Exp } \\
\text { Cal }\end{array}\right.\end{array}$ & & $\begin{array}{c}\mathrm{C}_{6} \mathrm{H}_{6} \\
20 \cdot 8 \\
21 \cdot 5\end{array}$ & $\begin{array}{c}\mathrm{C}_{8} \mathrm{H}, \mathrm{N} \\
21 \cdot 9 \\
22 \cdot 7\end{array}$ & $\begin{array}{l}\mathrm{N} \\
26 \\
26\end{array}$ & & & $\begin{array}{l}\mathrm{OH} \\
2 \\
2\end{array}$ & $\mathrm{H}_{2} \mathrm{O}$ \\
\hline
\end{tabular}

Research Department,

R. S. SILvER.

Cathcart,

Glasgow, S.4.

Dec. 9 .

\title{
Resolving Power of the Microscope using Polarized Light
}

IN a recent paper ${ }^{1}$ I derived formulæ expressing the distribution of light in the geometrical focal plane of optical systems of high relative aperture; and, using these formula, curves were given showing the distribution of light in directions perpendicular to, and parallel with, the direction of polarization for a system fulfilling the sine-condition, and of numerical aperture equal to $0 \cdot 77$. A conclusion drawn, on the basis of this work, was: "The curves... have bearing on the resolving power of microscopes. A variation of the resolution for two fixed points with rotation of the direction of polarization is suggested by them".

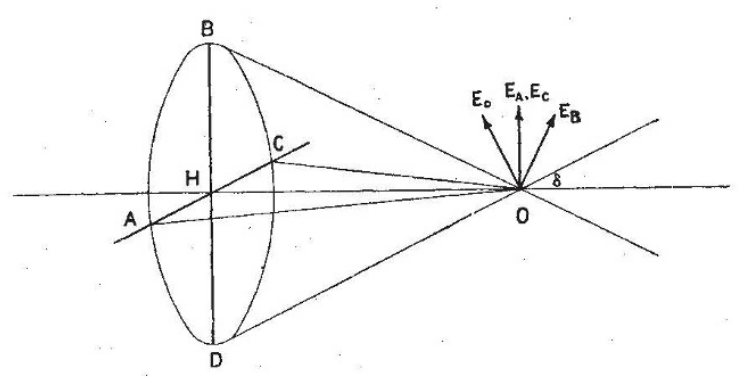

A paper has now come to my notice which confirms the existence of such a variation. In "An Application of Polarised Light to Resolution with the Compound Microscope"2, Stump refers to a note in Carpenter's "The Microscope and its Revelations" (p. 325, 1891 edition) which records, as an unexplained fact, that by placing a Nicol analysing prism over the eyepiece "the effect [of resolution] is much strengthened". Stump examined a number of objects having minute periodic structure, and "it was found that in all cases where the prism was set so as to pass light vibrating in a plane parallel to the striæ being shown, a clearer image was formed than when the prism was not used". This is fully in accord with the results I obtained mathematically, of which there seems possible a simple physical explanation.

In the diagram, $H B$ is the direction of vibration of the light vectors in the incident plane-polarized wave; and $A B C D$ is an annulus of the emergent converging spherical wave. Elements of the wave passing through $A, B, C, D$ proceed to the focus at $O$ along the ray-paths $A O, B O, C O, D O$. At $O$ the disturbances associated with $A, B, C, D$ are $E_{A}, E_{B}, E_{C}, E_{D}$; of which $E_{A}, E_{C}$ have full effect; whereas $E_{D}, E_{3}$ cancel along the direction $H O$, and along the direction of $E_{A}, E_{C}$ have effective magnitudes $E_{D} \cos \delta$ and $E_{B} \cos \delta$, where $\delta$ is the angular semi-aperture of the annulus $A B C D$. Thus, relative to the meridian $H C$, the effective amplitude along $H B$ is attenuated; and in the direction $H C$ there is a greater concentration of energy in the outer parts of the wave. This state of affairs leads to a narrower diameter of the Airy disk in the direction $H C$, and a (relatively) broader diameter in the direction $H B$. That is, striæ with their lengths in the direction $H B$ will be better resolved than those along $H C$.

Evidently the resolution with the prism in its position of maximum effect will be greater than that using non-polarized light. This was found to be the case by Stump (loc. cit.) : ". . . a clearer image of the striæ was formed than when the prism was not used".

Stump attempted a very inadequate and tentative explanation of the phenomenon, and urged the use of as many separate beams as there were structural elements - claiming that the final image "would then be a composite, formed by the blending of several independent images, each showing some particular element in the structure". A photograph of the surface structure of Amphipleura pellucida is given in support of the claim.

W. Watson and Sons, Ltd., H. H. Hopkins. High Barnet, Herts.

1 Proc. Phys. Soc., 55, 116 (1943).

${ }^{2}$ J. Roy. Mic. Soc., 264 (1922). 